\title{
Control of Secondary Phases by Solution Treatment in a N-Alloyed High-Mn Cryogenic Steel
}

\author{
Xiao-Jiang Wang ${ }^{1,2} \cdot$ Xin-Jun Sun ${ }^{2} \cdot$ Cheng Song $^{1} \cdot$ Shuai Tong ${ }^{2} \cdot$ Luo-Jin Liu $^{2} \cdot$ Huan Chen ${ }^{2} \cdot$ Wei Han $^{2} \cdot$ \\ Feng Pan ${ }^{1}$
}

Received: 15 March 2018/Revised: 27 April 2018/Published online: 29 May 2018

(C) The Chinese Society for Metals and Springer-Verlag GmbH Germany, part of Springer Nature 2018

\begin{abstract}
The secondary phases of the steels have significant effects on the microstructure and mechanical properties, making controlling these secondary phases important. The control of $\mathrm{MnS}$ inclusions and AlN precipitates in a N-alloyed high-Mn twin-induced plastic cryogenic steel via solution treatment was investigated with several different techniques including microstructural characterization, $298 \mathrm{~K}$ tensile testing, and $77 \mathrm{~K}$ impact testing. The solutionizing temperature (ST) increased from 1323 to $1573 \mathrm{~K}$, where the elongated MnS inclusions and large-sized AlN precipitates became spheroidized and dissolved. The aspect ratio of the MnS inclusions decreased as the ST increased and the number density increased. The impact toughness of the steels showed anisotropy and low impact energy values, due to the elongated MnS inclusions and large-sized AIN precipitates. The anisotropy was eliminated by spheroidizing the MnS inclusions. The impact energy was improved by dissolving the large-sized AlN precipitates during the solution treatment. The austenite grain size increased when the dissolution of the AlN precipitate increased, but the effect of the grain size on the yield strength, toughness, and the strength-ductility balance was weak.
\end{abstract}

Keywords Cryogenic $\cdot$ Solutionizing temperature $\cdot$ Low-temperature toughness $\cdot$ Spheroidize $\cdot$ Dissolution

\section{Introduction}

For decades, people have used Ni-based invar alloys, 9\% $\mathrm{Ni}$ alloys, or austenitic stainless steels to build pressure vessels for storing or transporting liquefied natural gas. However, these materials are quite expensive and welding consumable. There have been efforts focusing on inexpensive high-Mn steels that would replace these costly materials. The high-Mn steels have high strength, ductility, and toughness, although the development of high-Mn steels is limited by their relatively low yield strength [1-9].

Available online at http://link.springer.com/journal/40195

Xiao-Jiang Wang

wxj15@mails.tsinghua.edu.cn

$\triangle$ Xin-Jun Sun

sunxinjun@cisri.com.cn

1 Department of Materials Science and Engineering, Tsinghua University, Beijing 100084, China

2 Department of Structural Steels, Central Iron and Steel Research Institute, Beijing 100081, China
Frehser and Kubisch initially discovered that the yield strength could be increased by incorporating $\mathrm{N}$ in the high$\mathrm{Mn}$ austenitic steels, without an apparent decrease in toughness $[10,11]$. In order to increase the solubility of the element $\mathrm{N}$ in steelmaking, an appropriate content of element $\mathrm{Cr}$ should be added $[12,13]$. Also, the addition of $\mathrm{Cr}$ allows the corrosion resistance to increase [14].

The high concentrations of $\mathrm{Mn}, \mathrm{N}$, and $\mathrm{Cr}$ elements that are added in the steels could easily form the secondary phases with other alloying elements. The secondary phases have significant effects on the microstructure and the mechanical properties of steels [15]. The high-Mn concentration forms the MnS inclusion when combine with $\mathrm{S}$, even at low $\mathrm{S}$ contents. $\mathrm{Al}$ is easily combined with oxygen to form alumina, so $\mathrm{Al}$ is often added during steelmaking to deoxidize in the steel. The solute $\mathrm{Al}$ tends to form an AlN precipitate during hot machining when combined with $\mathrm{N}$. Due to the low precipitation temperature of $\mathrm{Cr}$ carbonitrides, they are completely dissolved during the solution treatment. Only the MnS inclusions and the AlN precipitates exist in $\mathrm{N}$-alloyed high-manganese steels. 
The MnS inclusions have excellent ductility, so they become elongated during deformation [16]. The elongated $\mathrm{MnS}$ inclusions cause significant anisotropy in the mechanical properties [17-20]. The effect of the AlN precipitate on precipitation strengthening is weaker than the effect of $\mathrm{N}$ on solution strengthening within $\mathrm{N}$-alloyed steel [21]. The voids are easily nucleated at the interface between the large-sized AIN precipitate and the matrix during the ductile fracture. The micro-void growth and the coalescence could deteriorate the mechanical properties of the steels [22]. Although the negative effect of the $\mathrm{MnS}$ inclusions can be weakened when the $\mathrm{S}$ content is reduced during steelmaking, but this will increase the difficulty in steelmaking. Also, it is difficult to eliminate the negative effects of the large-sized AIN precipitates by a low-temperature heat treatment [15]. Fortunately, the $\mathrm{MnS}$ inclusions and the large-sized AlN precipitates can be spheroidized and dissolved during the high-temperature solution treatment $[23,24]$. Compared with elongated $\mathrm{MnS}$ inclusions, the effect of the spheroidized $\mathrm{MnS}$ inclusions on the anisotropy in mechanical properties is insignificant [25]. The dissolution of the large-sized AlN precipitate improves the fracture ductility and the toughness.

Up to now, there have been few studies on the negative effect of secondary phases on mechanical properties by solution treatment in the $\mathrm{N}$-alloyed high-Mn cryogenic steel. In this study, the change of the morphology of $\mathrm{MnS}$ inclusions during solution treatment was characterized by in situ observation microscope. Thermo-Calc software was used to calculate the volume fraction of the AIN precipitate with different STs. The tensile test and the Charpy impact test were performed at $298 \mathrm{~K}$ and $77 \mathrm{~K}$. The effects of $\mathrm{MnS}$ inclusion and AlN precipitate on the microstructures and the mechanical properties were discussed.

\section{Experimental Procedure}

The N-alloyed high-Mn steels were prepared to study the control of $\mathrm{MnS}$ inclusion and AlN precipitate by solution treatment. Each composed specimen was made by casting in a 100-kg induction melting furnace within Ar atmosphere, and the steel ingots were hot-forged into $120 \times 110 \times 60 \mathrm{~mm}^{3}$ blocks. Inductively coupled plasma-atomic emission spectrometer (ICP-AES) was

Table 1 Chemical compositions of the materials (wt\%)

\begin{tabular}{lllllllll}
\hline $\mathrm{C}$ & $\mathrm{Si}$ & $\mathrm{Mn}$ & $\mathrm{S}$ & $\mathrm{P}$ & $\mathrm{Cr}$ & $\mathrm{Mo}$ & $\mathrm{N}$ & $\mathrm{Al}$ \\
\hline 0.48 & 0.21 & 24.28 & 0.0091 & 0.0059 & 6.29 & 0.32 & 0.19 & 0.024 \\
\hline
\end{tabular}

employed to measure chemical compositions (wt\%), as shown in Table 1.

Figure 1a shows the rolling and solution treatment processes. After soaking at $1473 \mathrm{~K}$ for $1 \mathrm{~h}$, the billets were hot-rolled to a plate with a thickness of $12 \mathrm{~mm}$ and total reduction ratio of $80 \%$ and then quenched into water to room temperature. Then, the plates were carried on solution treatment at 1323, 1373, 1423, 1473, 1523 and $1573 \mathrm{~K}$, respectively. Confocal scanning laser microscope (CSLM) was used to conduct the in situ observations of the evolution of $\mathrm{MnS}$ inclusions during the heating process. The dimension of the specimens was $\$ 5 \mathrm{~mm} \times 3 \mathrm{~mm}$. After being mirror-polished and ultrasonically washed, the specimens were heated to $1573 \mathrm{~K}$ and hold for $2 \mathrm{~min}$ in an alumina crucible under ultrahigh-purity $\mathrm{Ar}$ gas. The experimental process is shown in Fig. 1b. The inclusions were analyzed by HITACHI S-4300 scanning electron microscope (SEM) and energy-dispersive X-ray spectroscopy (EDS).

The metallographic observations were performed by using OLYMPUS GX51 optical microscope (OM) and SEM. Electron-backscattered diffraction (EBSD) in a FEI Quanta 650FEG field emission SEM was used to characterize microstructure. The raw EBSD data were processed by orientation averaging using the VMAP software to reduce orientation noise. Further analysis of these EBSD data was carried out by HKL software (Channel 5). Carbon extraction replicas were prepared for precipitate analysis including precipitate types and size distribution. The specimens were polished and then etched in $4 \%$ nital for $5 \mathrm{~min}$. A carbon coating about $20 \mathrm{~nm}$ in thickness was deposited on surface by using an evaporator operated at a high vacuum. The carbon film coated surfaces of specimens were scribed by using a blade to produce squares about $2 \times 2 \mathrm{~mm}^{2}$ in size. The replicas were released in $4 \%$ nital etched solution and then cleaned in distilled water. The replicas were placed on copper $(\mathrm{Cu})$ grids and then analyzed in a transmission electron microscopy (TEMTecnai $\mathrm{G}^{2} \mathrm{~F} 20$ ). The particle size of the precipitates was measured by a quantitative image analyzer. In addition, chemical analysis for the precipitates was conducted by using nano-beam EDS analysis.

The tensile tests were performed by using a WE-300 tensile test machine in ambient atmosphere. The testing speed was $2 \mathrm{~mm} / \mathrm{min}$, and extensometer was used to measure the elongation. The tensile specimens with a $\Phi 8 \mathrm{~mm}$ and Charpy V-notch specimens with $10 \times 10 \times 55 \mathrm{~mm}^{3}$ were machined from rolled plate along with $0^{\circ}, 45^{\circ}$ and $90^{\circ}$ directions. $\left(0^{\circ}\right.$ represents rolling direction, $45^{\circ}$ and $90^{\circ}$ represent a rotation of $45^{\circ}$ and $90^{\circ}$ along the rolling direction, respectively.) Charpy impact tests were performed by using a JBN-300N under $77 \mathrm{~K}$. 

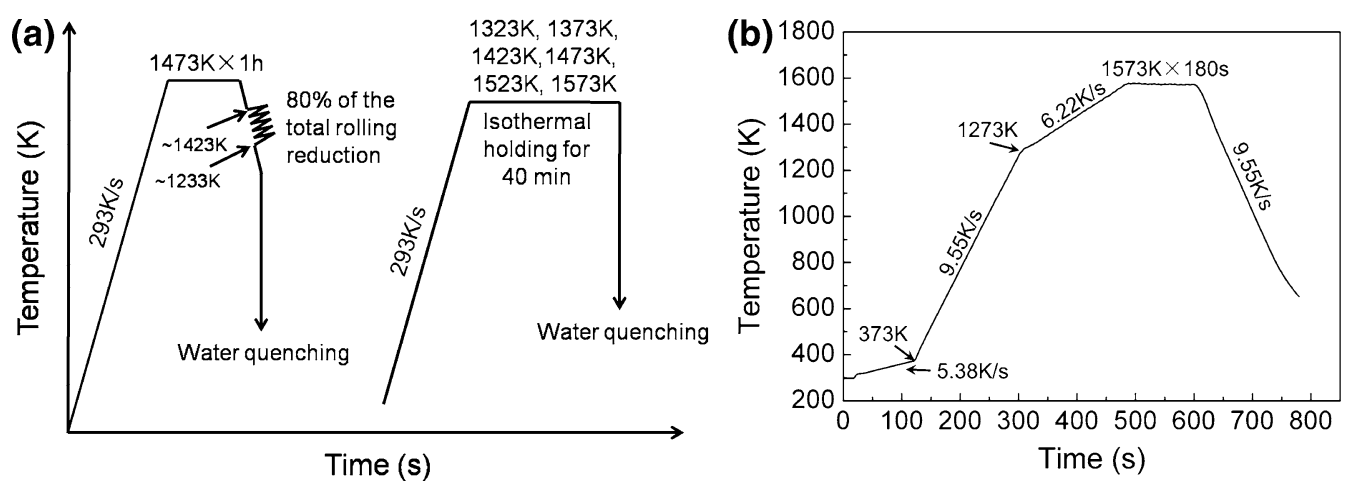

Fig. 1 Rolling and solution treatment processes $\mathbf{a}$ and in situ observation experiment process $\mathbf{b}$

\section{Results and Discussion}

\subsection{Hot-Rolled Steel}

Figure 2 shows the microstructure, the $\mathrm{MnS}$ inclusion, and the AlN precipitate of the hot-rolled steel. The microstructure of steels consisted of randomly oriented equiaxial austenite grains. There were large numbers of $\mathrm{MnS}$ inclusions and AlN precipitates within the experimental steels. The morphologies of the MnS inclusions were elongated, parallel to the rolling direction. The $\mathrm{MnS}$ inclusions formed during the steelmaking and then elongated during high-temperature rolling. The nanomeasurer 1.2 was used to measure the sizes of $\mathrm{MnS}$ inclusions. Their average lengths and widths were 47 and $2.1 \mu \mathrm{m}$. The number density of $\mathrm{MnS}$ inclusions is $13 \mathrm{~mm}^{-2}$. White spots in Fig. 2 were AlN precipitates. The $\mathrm{N}$-containing austenitic steels showed that the soluted $\mathrm{Al}$ atoms tended to form AlN precipitates combined with $\mathrm{N}$ atoms during the hot machining. The AlN was precipitated during the rolling of the experimental steels.
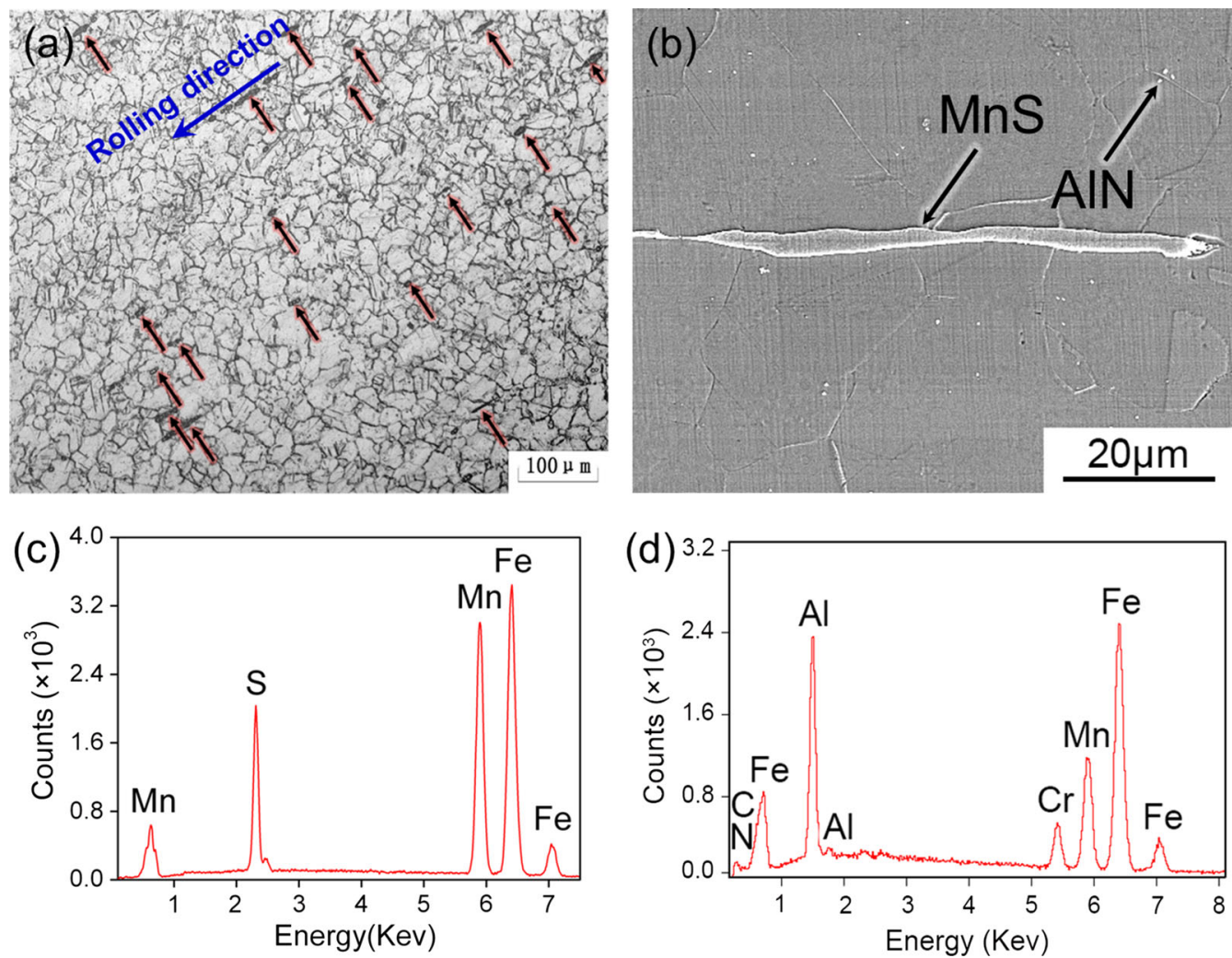

Fig. 2 Microstructure, MnS inclusion, and AlN precipitate of the hot-rolled steel. a OM image (the red arrow refers to MnS inclusion), b SEM image of MnS inclusion and AlN precipitate, $\mathbf{c}, \mathbf{d}$ are the EDS spectra of MnS inclusion and AlN precipitate shown in $\mathbf{b}$ 


\subsection{The Effect of Solution Treatment on the Morphology of MnS Inclusions and the Precipitation of AIN}

\subsubsection{The Spheroidization of MnS Inclusion}

The elongated MnS inclusion in the steels deteriorated the mechanical properties and caused anisotropy in the mechanical properties [26]. Previous studies found that the elongated $\mathrm{MnS}$ inclusions were spheroidized by the solution treatment, where the effects of the spheroidized $\mathrm{MnS}$ inclusions are insignificant on the anisotropy in the mechanical properties [23-25]. It would be helpful to have an appropriate solution treatment that would result in spheroidized MnS inclusions. Due to the solution treatment of the $\mathrm{MnS}$ inclusion and the AlN precipitate at high temperature, the lowest temperature was chosen to be $1323 \mathrm{~K}$. The highest ST was maintained at $1573 \mathrm{~K}$, so that the experimental steels did not melt. The range of ST was from 1323 to $1573 \mathrm{~K}$.

Figure 3 shows the SEM images of the MnS inclusions in different specimens with a solution treatment range from 1323 to $1573 \mathrm{~K}$. After the solution treatment at $1323 \mathrm{~K}$, the length of $\mathrm{MnS}$ inclusions decreased, but both tails remained sharp shape. When treated at $1373 \mathrm{~K}$, the $\mathrm{MnS}$ inclusions began to shrink and spheroidize significantly. Then, they were broken into two parts during the $1423 \mathrm{~K}$ solution treatment. The $\mathrm{MnS}$ inclusions continued to break when the solution temperature increased to $1473 \mathrm{~K}$. The morphology of the ruptured $\mathrm{MnS}$ inclusions changed into short rods when the temperature rose to $1523 \mathrm{~K}$. The short rod-like $\mathrm{MnS}$ inclusions changed into ellipsoidal, when the $\mathrm{ST}$ increased to $1573 \mathrm{~K}$. The results indicated that the $\mathrm{MnS}$ inclusion spheroidized when the ST was increased. The average sizes, the aspect ratios, and the number densities of $\mathrm{MnS}$ inclusion with different STs are shown in Fig. 4. Figure $4 \mathrm{a}$ shows that the length of the $\mathrm{MnS}$ inclusion decreased when the ST increased, but the width of the MnS inclusion increased. The aspect ratios of the $\mathrm{MnS}$ inclusion decreased when the ST increased (see Fig. 4b). But the number densities were increased with the increase in ST, which was resulted from the segmentation of the elongated $\mathrm{MnS}$ inclusion (see Fig. 4c). The results showed that the effect of the solution treatment on the spheroidization of the MnS inclusions was significant.

The change of the MnS inclusion morphology during the solution treatment was characterized by performing in situ observation experiments. The oxygen content was low in Al-deoxidized steels, so there were minor amounts of $\mathrm{Al}_{2} \mathrm{O}_{3}$ inclusions in the steels. The morphologies of the $\mathrm{Al}_{2} \mathrm{O}_{3}$ inclusions were ellipsoidal. Their ST was higher than that the MnS inclusion spheroidization. The morphology changes of the MnS inclusions during in situ observation experiments were observed with a MnS inclusion coated with $\mathrm{Al}_{2} \mathrm{O}_{3}$. Figure $5 \mathrm{a}-\mathrm{g}$ shows the CSLM images of the $\mathrm{MnS}$ inclusions at the temperatures ranging from 297.6 to $1573 \mathrm{~K}$. When the temperature was increased to $1323 \mathrm{~K}$, the morphologies of $\mathrm{MnS}$ inclusions changed. Their lengths decreased, while the widths increased. The ST rose from 1323 to $1573 \mathrm{~K}$, which decreased the length of the $\mathrm{MnS}$ and increased the width. The MnS inclusions were spheroidized. After holding $2 \mathrm{~min}$ at $1573 \mathrm{~K}$, the spheroidization of $\mathrm{MnS}$ inclusions was larger than that at $1573 \mathrm{~K}$ (see Fig. 5h). Figure 5i shows the SEM and the corresponding EDS spectrum of the $\mathrm{MnS}$ inclusions after cooling down. The $\mathrm{MnS}$ inclusions dissolved largely, while the $\mathrm{Al}_{2} \mathrm{O}_{3}$ inclusions changed slightly. The remaining holes were filled by the matrix microstructure following the dissolution of the $\mathrm{MnS}$ inclusions. The results showed that the spheroidization of the MnS inclusions was promoted when the ST was increased and the holding time was prolonged.

Shape changes of the elongated $\mathrm{MnS}$ were caused by surface diffusion of the Mn atoms and the S atoms [27]. The higher ST yielded greater diffusion rates of the Mn atoms and the S atoms [28]. The chemical potential on the surface of the MnS was obtained with the Gibbs-Thompson relation [29].

$\mu=\mu_{0}+\Omega \gamma K$

where $\mu_{0}$ represented the chemical potential of a flat surface, $\Omega$ was the molecular volume, $\gamma$ was the surface tension, and $K$ was the total curvature. According to Eq. (1), the larger $K$ was, the greater the driving force obtained for the diffusion. It indicated that the spheroidization of the $\mathrm{MnS}$ inclusions started at the site where the $K$ was the biggest. The length of the MnS inclusions shrank as the ST continuously increased continuously. The $\mathrm{Mn}$ and the $\mathrm{S}$ atoms continued to diffuse to both sides of the elongated $\mathrm{MnS}$, where their average width increased. So, the $\mathrm{MnS}$ inclusions spheroidized significantly during solution treatment.

\subsubsection{The Dissolution of AIN Precipitate}

The AlN precipitate in the hot-rolled steels could be dissolved during high-temperature heat treatment. As shown in Fig. 3, the white spots were AlN precipitates. A large number of AlN precipitates were distributed in the grains interior and the grain boundaries. The ST increased from 1323 to $1473 \mathrm{~K}$, as the number of AlN particles decreased. When the solution temperature was at $1523 \mathrm{~K}$ and above, the AlN precipitates were completely dissolved. Figure $6 \mathrm{a}-$ $\mathrm{d}$ shows the morphologies, the diffraction pattern, and EDS of the AlN precipitates in the steel with a $1323 \mathrm{~K}$ solution 

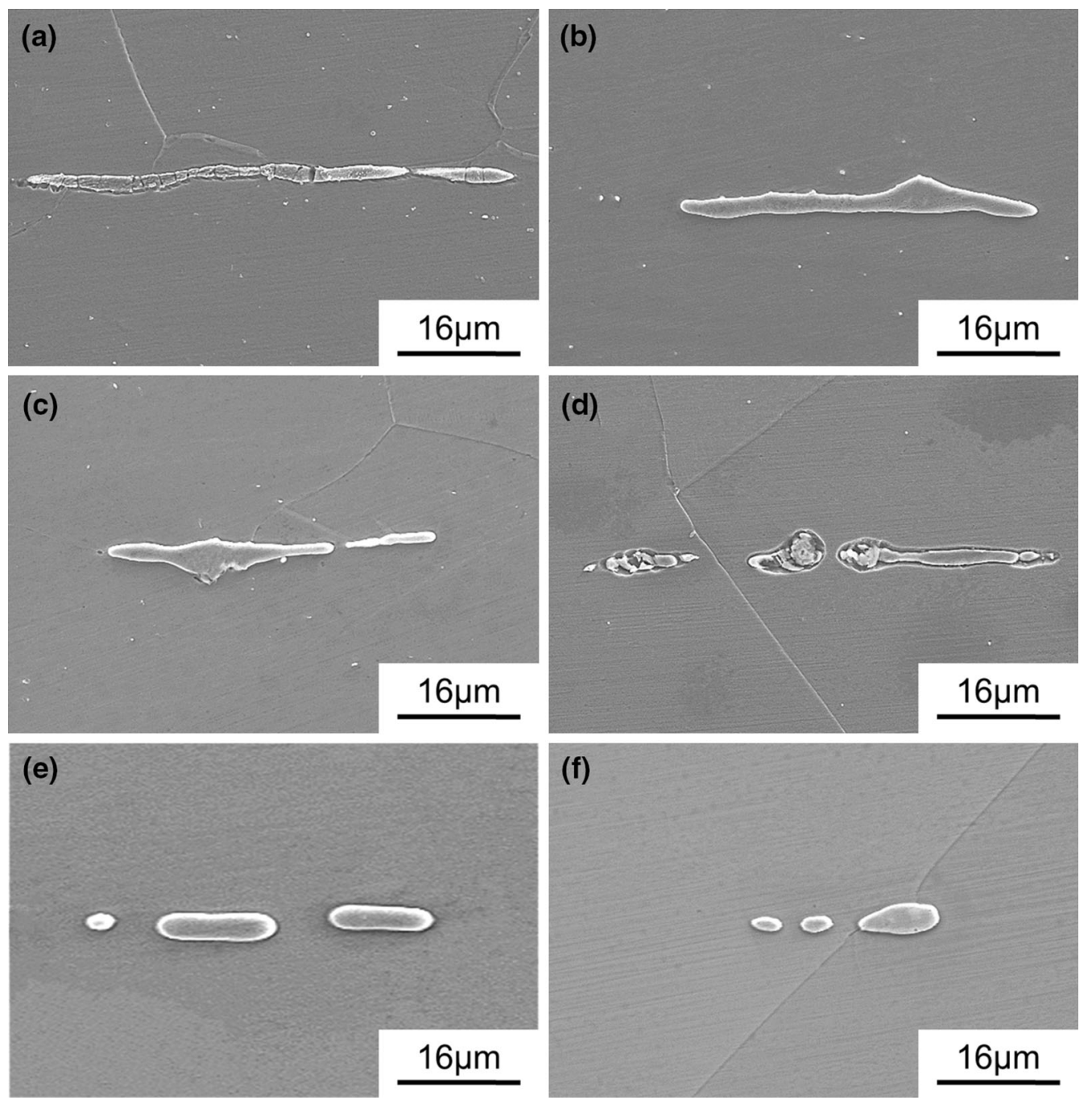

Fig. 3 SEM images of MnS inclusions and AlN precipitates in the different specimens with various STs. a $1323 \mathrm{~K}$, b $1373 \mathrm{~K}$, c $1423 \mathrm{~K}$, d $1473 \mathrm{~K}$, e $1523 \mathrm{~K}$, f $1573 \mathrm{~K}$

treatment. The $\mathrm{Cu}$ peaks were associated with the TEM holder and the $\mathrm{Cu}$ grid. The average size of the larger AlN precipitates was $\sim 250 \mathrm{~nm}$. The AlN particles shown in Fig. 3 were the large-sized precipitates. The average size of the smaller AlN precipitates was $\sim 10 \mathrm{~nm}$ (see Fig. 6b). These small-sized precipitates have rarely been observed in TEM. As indicated in Fig. 6c, the diffraction pattern showed that the AlN precipitates had a typical closepacked hexagonal structure.

To investigate the effect of solution treatment on the precipitation and dissolution of AlN, the volume fraction of the AlN precipitate with various STs should be clear. The volume fraction of the AlN precipitate-temperature curve of the experimental steel is shown in Fig. 6e, as calculated by the Thermo-Calc software. The volume fraction of the AlN precipitate decreased as the ST increased. The solutionizing starting temperature of the AlN precipitate was $\sim 1023 \mathrm{~K}$. The termination temperature was $\sim 1493 \mathrm{~K}$.
Theoretically, the AlN precipitate could dissolve completely when the ST exceeded $1493 \mathrm{~K}$. The calculated results were in accordance with the experimental results shown in Fig. 3.

\subsection{The Effect of MnS Inclusion Spheroidization and AIN Dissolution on Microstructures and Mechanical Properties}

\subsubsection{The Effects of MnS Inclusion and AIN Precipitate on the Impact Toughness}

The mechanical properties of the hot-rolled steels at various directions are listed in Table 2. The yield strength, the tensile strength, the elongation, and the impact energy of the experimental steels exceeded $\sim 437, \sim 941 \mathrm{MPa}$, $\sim 67 \%$, and $53 \mathrm{~J}$, respectively. The changes between the strength and the toughness with respect to the various 
(a)

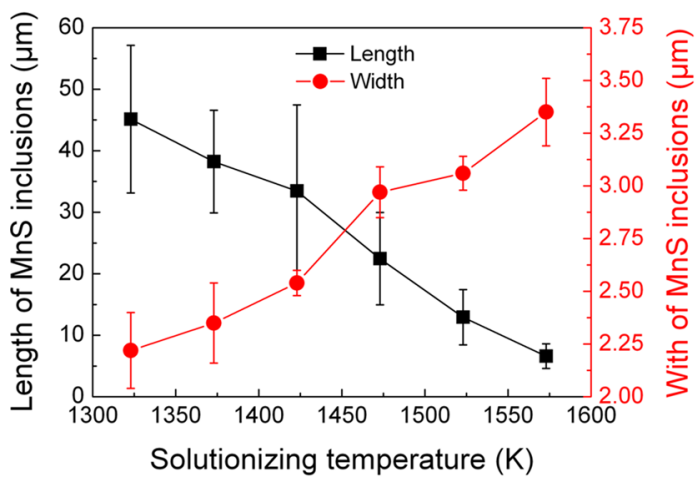

(b)

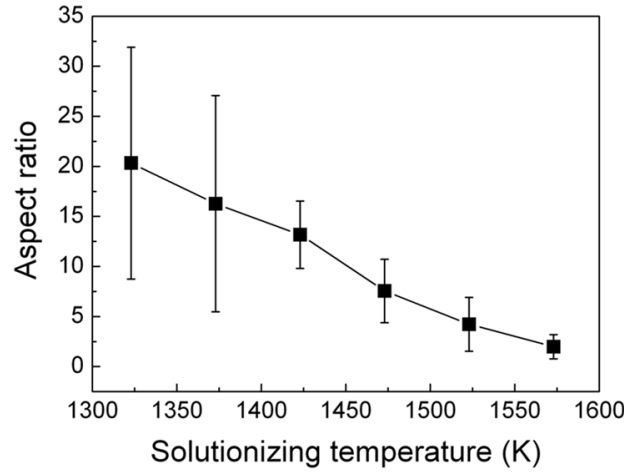

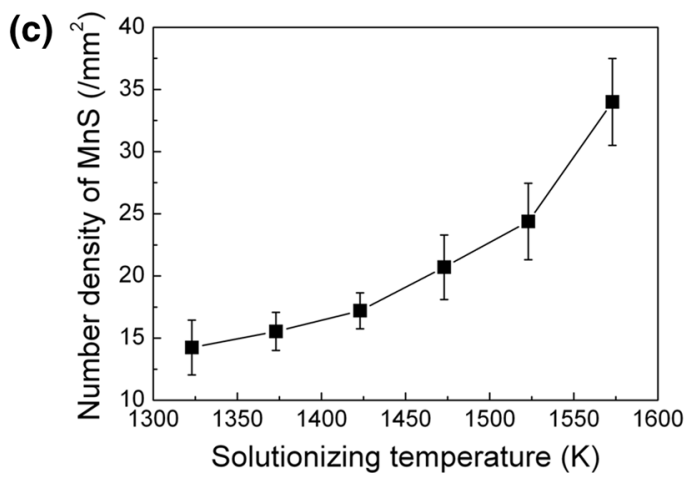

Fig. 4 Average sizes a, aspect ratios $\mathbf{b}$, and number densities $\mathbf{c}$ of MnS inclusion with various STs

directions in hot-rolled steel sheets were studied. The relationships among the strength, impact energy, and direction are summarized in Fig. 7. The yield strength, the tensile strength, and the elongation changed slightly as the angle increased, but the impact energy decreased significantly. The difference percentage $(\Delta D)$ between the two values of the impact energy along different directions is calculated as follows:

$\Delta D_{a}=\frac{E_{a}-E_{90^{\circ}}}{E_{a}}$

where the $E_{a}$ was the impact energy along the $0^{\circ}$ or the $45^{\circ}$ directions; $a$ was the angle. Theoretically, if there was no anisotropy of the impact toughness in the steels, then the value of $\Delta D$ would be zero. According to the equation, the $\Delta D_{0^{\circ}}$ and the $\Delta D_{45^{\circ}}$ were 45.9 and $26.4 \%$, respectively. The results indicated that the impact toughness of the hotrolled steels demonstrated significant anisotropy. The causes for the impact toughness anisotropy are discussed as follows.

The anisotropy of the mechanical properties was generally influenced by the microstructure, textures, and the elongated $\mathrm{MnS}$ inclusions [30]. The finishing rolling temperature of the hot-rolled steel was $\sim 1233 \mathrm{~K}$ (see Fig. 1a). The microstructure of the hot-rolled steel was equiaxial austenite (see Fig. 2). This indicated that the density of the texture in the steels was low. The effect of the microstructure on the anisotropy of the mechanical properties was insignificant. Figure 8 shows the $77 \mathrm{~K}$ impact test fracture morphologies of the hot-rolled steels along various directions. The fracture morphologies were a ductile fracture pattern. A large quantity of dimples existed on the fracture surface. The large-sized dimples on the fracture at the $0^{\circ}$ direction were ellipsoidal. The fracture at the $45^{\circ}$ direction had ellipsoidal dimples and elongated dimples. The fracture at $90^{\circ}$ direction only contained the elongated dimples. According to the results shown in Fig. 2, the elongated $\mathrm{MnS}$ inclusions existed within the steels. The shapes of these dimples were determined by the fracture model of the $\mathrm{MnS}$ inclusions along various directions [31]. The crack propagation direction was perpendicular to the length direction of the $\mathrm{MnS}$ inclusions when the impact test was performed on a specimen machined from the $0^{\circ}$ direction. The elongated $\mathrm{MnS}$ inclusions were broken into two parts, where two largesized ellipsoidal dimples were formed in the fracture. When the specimens machined from $90^{\circ}$ direction, the crack propagation direction was parallel to the length direction of the $\mathrm{MnS}$ inclusions. The crack propagated forward, along the boundaries between the MnS and the matrix. The morphology of the $\mathrm{MnS}$ inclusions changed slightly, where elongated dimples were formed on the 

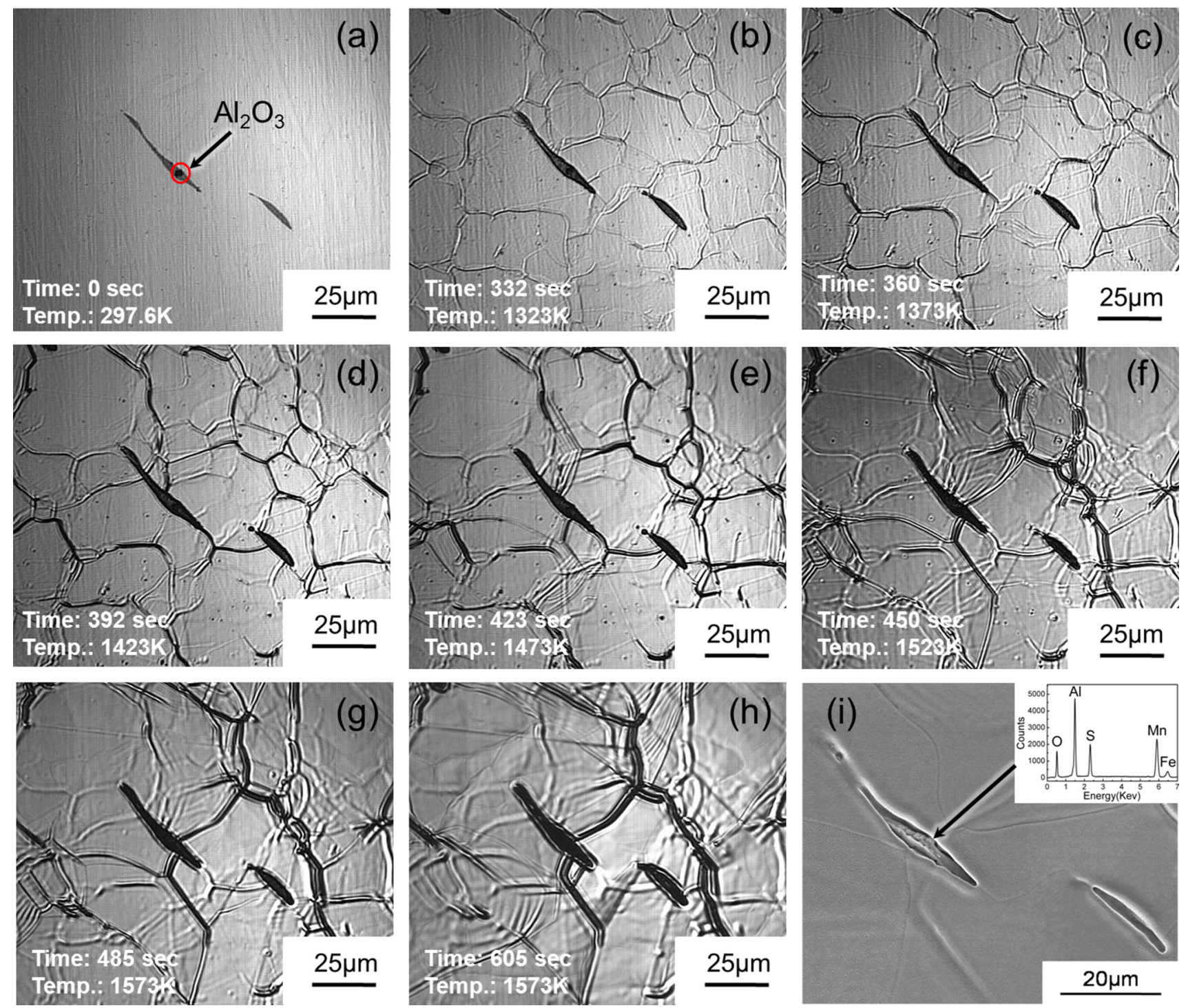

Fig. 5 CSLM images (a $297.6 \mathrm{~K}$, b $1323 \mathrm{~K}$, c $1373 \mathrm{~K}$, d $1423 \mathrm{~K}$, e $1473 \mathrm{~K}$, f $1523 \mathrm{~K}$, g $1573 \mathrm{~K}$, h $1573 \mathrm{~K}+2$ min) and the images of SEM (include EDS spectrum) $\mathbf{i}$ of $\mathrm{MnS}$ inclusion after cooling down

fracture. Both ellipsoidal and elongated dimples existed at the $45^{\circ}$ angle. It is expected that cracks are more easily propagated along the boundaries between them and matrix. Therefore, the impact energy decreased significantly as the angle increased. These results indicated that the anisotropy of the impact toughness was caused by the elongated $\mathrm{MnS}$ inclusions.

The Charpy impact energy of the experimental steels as shown in Fig. 9a improved slightly with the increase in ST from 1323 to $1473 \mathrm{~K}$. However, when the ST exceeded $1473 \mathrm{~K}$, both increments were largely. In our previous work, the results showed that the change in the grain size of the austenitic steel had little effect on the impact toughness [32]. According to the results of Fig. 3, when the ST exceeds $1473 \mathrm{~K}$, the MnS inclusions can be dissolved into several segments, and the average lengths were decreased significantly. So, the impact energies are improved significantly by the dissolution of $\mathrm{MnS}$ inclusions. Figure $9 \mathrm{~b}$ shows the different percentages of the impact energy that had different directions. As shown in Fig. 9b, the $\Delta D$ decreased as the ST increased. When the ST increased to $1573 \mathrm{~K}$, the $\Delta D$ decreased more than any other temperatures. The change of the impact toughness anisotropy was in accordance with the spheroidization of the MnS inclusions. The spheroidized MnS inclusions were small and had a weak effect on the crack propagation. The results showed that the spheroidization of the MnS inclusions reduced the anisotropy of the impact toughness. The hightemperature solution treatment could be used to eliminate 

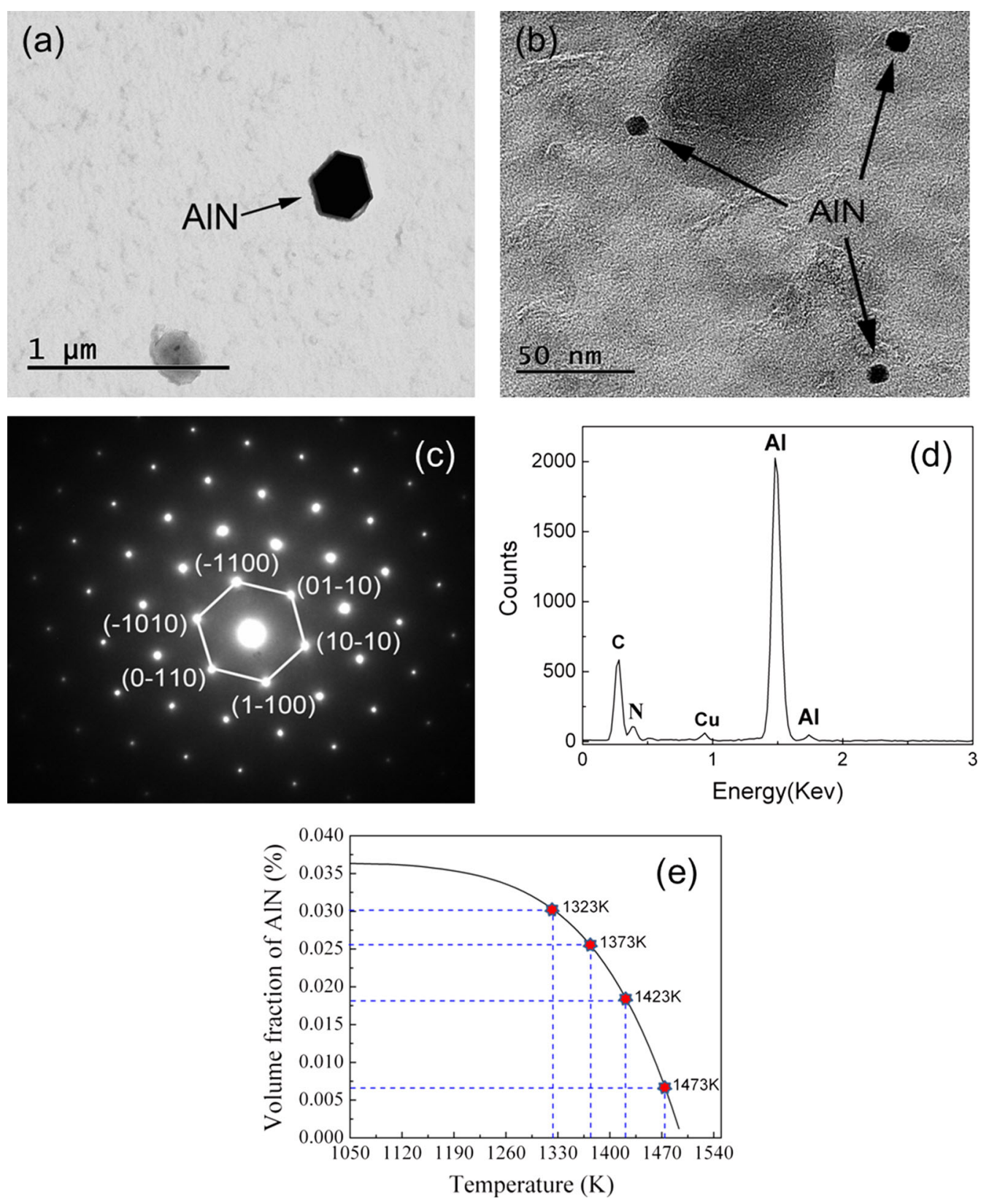

Fig. 6 Morphologies (large size a and small size b), selected area detection diffraction pattern $\mathbf{c}$ and EDS d of AlN precipitate in the steel with $1323 \mathrm{~K}$ solution treatment. The volume fraction of AlN precipitates versus temperature curve calculated by Thermo-Calc software $\mathbf{e}$

Table 2 Mechanical properties of the hot-rolled steels with various directions

\begin{tabular}{lllll}
\hline Angle $\left(^{\circ}\right)$ & Yield strength $(\mathrm{MPa})$ & Tensile strength $(\mathrm{MPa})$ & Elongation $(\%)$ & Impact energy $(\mathrm{J})$ \\
\hline 0 & 438 & 954 & 67 & 98 \\
45 & 437 & 941 & 68 & 72 \\
90 & 440 & 948 & 68 & 53 \\
\hline
\end{tabular}

the negative effect of the elongated MnS inclusions on the impact toughness anisotropy.

The impact fractures of the specimens that were parallel to the $0^{\circ}$ direction, with various STs, are shown in Fig. 10. A large number of the dimples existed on the fracture. The size of the dimples increased as the ST increased. A large quantity of large-sized AlN precipitates were seen in the dimples on the impact fractures in the steels that had the solution treatment ranging from 1323 to $1473 \mathrm{~K}$. The amount of AlN precipitates decreased as the ST increased. 


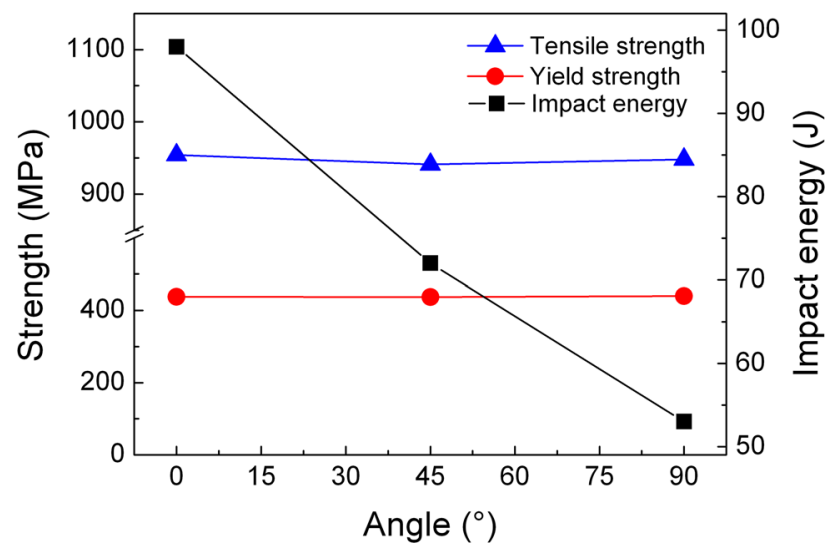

Fig. 7 Tensile strength, yield strength and impact energy of the hotrolled steels along various directions

When the ST was increased above $1523 \mathrm{~K}$, there were no large-sized AlN precipitates within the impact fractured steels. In the ductile fracture model, the dimples originated from the presence of the large-sized second-phase particles [22]. The large-sized AlN precipitates were referred as primary particles in this paper. The voids preferentially nucleated at the AlN particles. When the growing voids
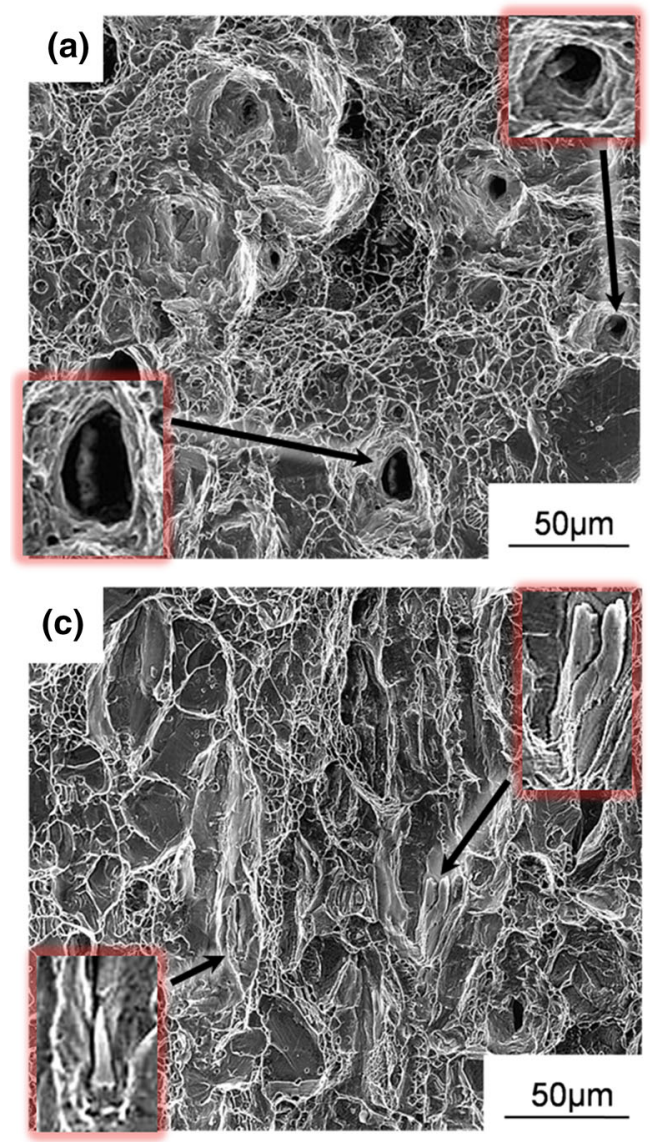

reached a critical size, a local plastic instability developed among the voids, resulting in failure. The larger the number of large-sized AlN particles, the easier the cracks propagated, and the lower the impact energy that was obtained. The toughness of the experimental steels improved when the ST increased from 1523 to $1573 \mathrm{~K}$ (see Fig. 9a). This indicated that the dissolution of the large-sized AlN particles improved the low-temperature toughness. The improvement of the impact toughness benefited from the spheroidization of MnS inclusions, as the ST increased.

\subsubsection{The Effect of MnS Inclusion and AIN Precipitate on Austenite Grain Size and Tensile Properties}

Figure 11 shows the EBSD images of the austenite grains and the annealing twins of the experimental steels with solution treatment ranging from 1323 to $1573 \mathrm{~K}$. The austenite grains grew significantly as the ST increased. The density of the annealing twins decreased as the ST increased. The austenite grain sizes of the experimental steels were measured via the linear intercepted method (as well as counting the grain and the twin boundaries). As
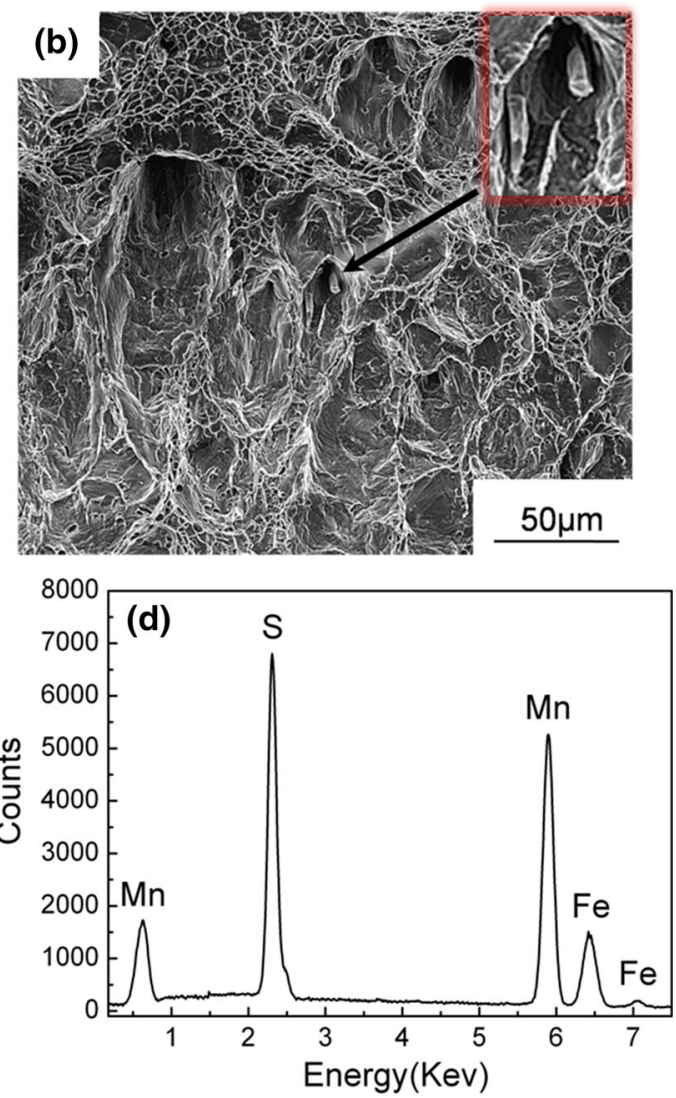

Fig. $877 \mathrm{~K}$ impact fracture morphologies of hot-rolled steels along various directions. a $0^{\circ}, \mathbf{b} 45^{\circ}, \mathbf{c} 90^{\circ}$ and d EDS of MnS inclusions. The black arrow refers to $\mathrm{MnS}$ inclusion 

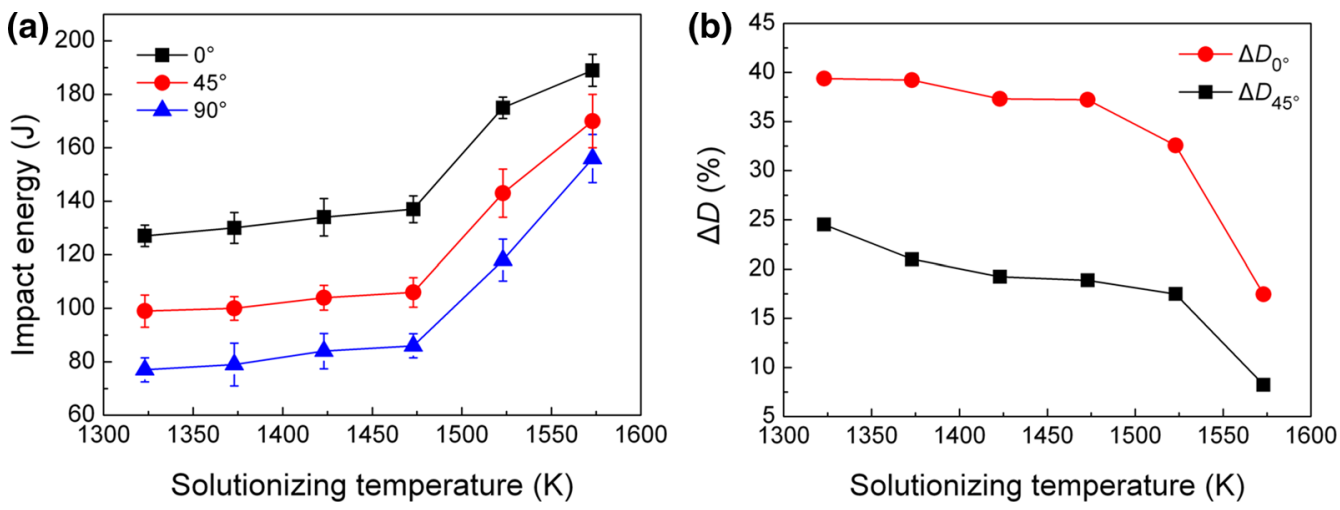

Fig. 9 Impact energies of experimental steels along different directions with various STs a and the different percentages of the impact toughness along various directions $\mathbf{b}$

shown in Fig. 12, the increment in the grain size between the adjacent temperatures was small when the ST increased from 1323 to $1473 \mathrm{~K}$. When the ST reached to $1523 \mathrm{~K}$ or higher, some of the austenite grains grew abnormally. The nano-sized AlN precipitates refined the grain size by impeding the grain-boundary movement. The small increment in the grain size between the adjacent temperatures ranging from 1323 to $1473 \mathrm{~K}$ caused the pinning effect of the AlN precipitate. The abnormal growth of the grain size was caused by the dissolution of AlN precipitates, which caused the disappearance of the pinning effect. The MnS inclusions were a microscale precipitate, so the effect on the grain refinement was insignificant.

The secondary phases refined the austenite grain, while affecting the tensile properties of the high-Mn steels. The room-temperature tensile properties of the experimental steels with various STs are listed in Table 3. The yield strength, the tensile strength, and the strength-ductility balance of the experimental steels exceeded $\sim 397$, $\sim 783 \mathrm{MPa}$, and $\sim 59.4 \mathrm{GPa} \%$, respectively. The elongation of the experimental steels increased from 68 to $79 \%$ as the ST increased. The effect of the grain size on ductility was insignificant within the high-manganese austenitic steels [32]. Similar to the impact energy, the elongation was also affected by the MnS inclusion and the AlN precipitate. The spheroidized MnS inclusions and the dissolved AlN precipitates both reduced the quantity of crack nucleation and propagation more than the elongated $\mathrm{MnS}$ inclusion and the large-sized AlN precipitate. The elongation of the experimental steels increased when the ST increased.

Figure 13a shows the room-temperature tensile engineering stress versus the strain curves. As shown in Fig. 13a, the steels exhibited a continuous yielding behavior, followed by extensive strain hardening. When the tension reached the maximum, the specimens rapidly fractured after necking. In our previous work, the experimental steel was proven to be a twin-induced plastic steel
[33]. The experimental steels could not undergo martensitic transformation even in both deformed and low-temperature environments. The true stress and the strain hardening rate (SHR) versus the true strain curves are shown in Fig. 13b. It could be seen that the SHR decreased with an increase in ST. Gwon et al. [34] indicated that the SHR was affected by the precipitate and the grain size in twin-induced plastic steels. They stated that the precipitate and the small austenite grain size hinder the slip of dislocations and mechanical twins, but then improve the SHR. The austenite grain grew when the volume fraction of AlN precipitate decreased. When the amount of AIN particles increased, the SHR increased. The relationships between the experimental steels were collated in order to study the effect of the ST on their strength (see Fig. 13c). The tensile strength of the experimental steels decreased as the ST increased. According to Mosecker et al. [35] and Ghasri-Khouzani et al. [36], the higher the SHR is, the higher the tensile strength is obtained. Accordingly, the tensile strength increased as the SHR increased.

Although the tensile strength decreased as the ST increased, the elongation increased inversely (see Table 3 ). The strength-ductility balance, the product of tensile strength and the total elongation, was used to characterize the energy absorbed during the tensile test. As shown in Fig. 13c, the strength-ductility balance did not decrease as the ST increased. When the temperature exceeds $1423 \mathrm{~K}$, the strength-ductility balance increased when the ST increased. The results indicated that the effect of the AlN precipitates on the strength-ductility balance was weak.

The decrement of yield strength was relatively small compared to the ultimate tensile strength. The yield strength exceeded $\sim 397 \mathrm{MPa}$. The yield strength of the $\mathrm{Fe}-\mathrm{Mn}-\mathrm{C}$ austenitic steels was $\sim 300 \mathrm{MPa}$ [37]. The increment of yield strength of the $\mathrm{N}$-alloyed high-Mn steels was 97-123 MPa. The yield strength was improved by complex strengthening mechanisms, such as solid solution, grain boundary, precipitation, and dislocation 

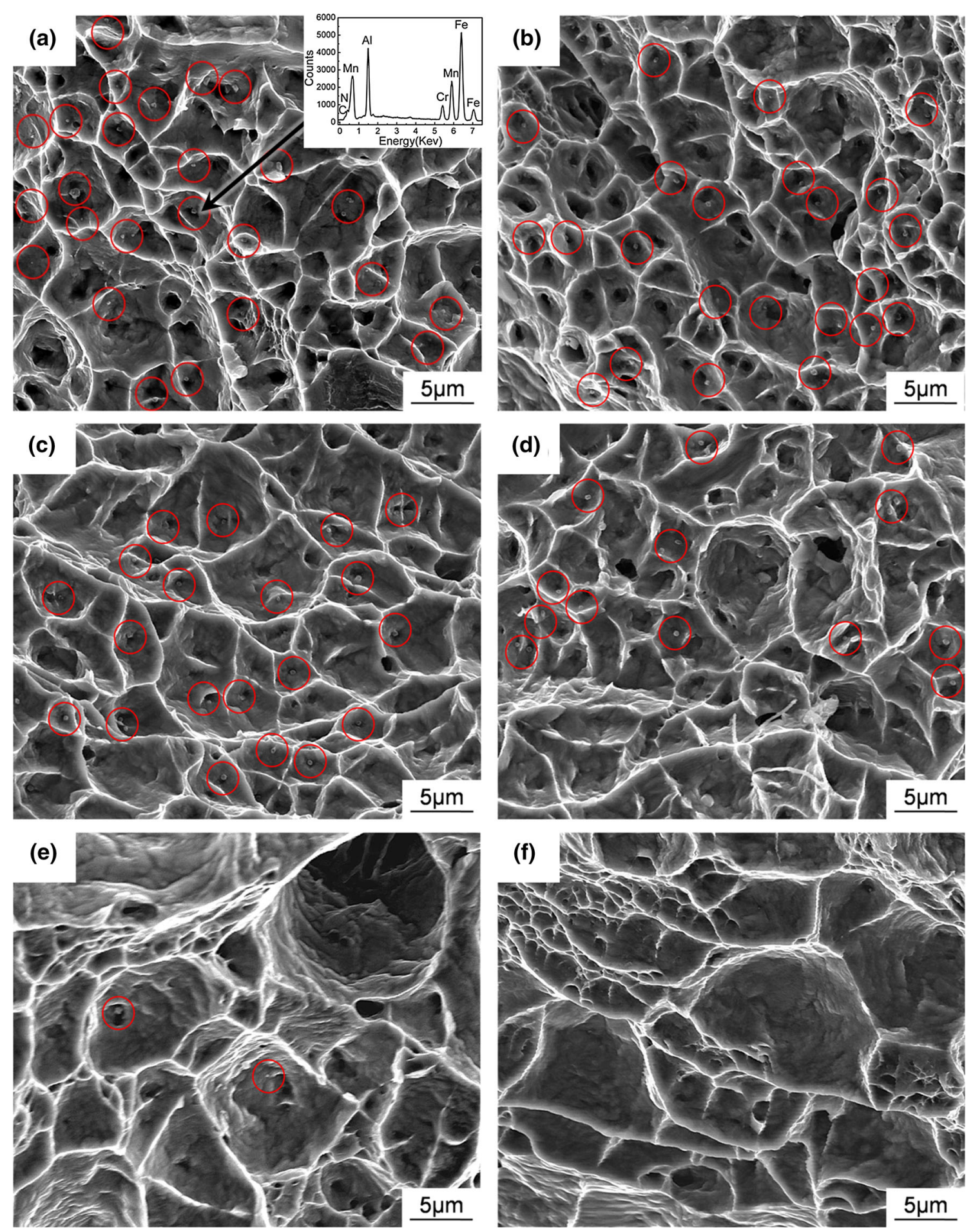

Fig. 10 Impact fractures of the specimens at $0^{\circ}$ direction in the experimental steels with various STs (red circles represent AlN precipitates). a $1323 \mathrm{~K}$, EDS of AlN precipitates, b $1373 \mathrm{~K}$, c $1423 \mathrm{~K}$, d $1473 \mathrm{~K}$, e $1523 \mathrm{~K}$, f $1573 \mathrm{~K}$

strengthening. The solid solution, the grain boundary, and the precipitation strengthening were related to the effect of the soluted $\mathrm{N}$ and the AlN precipitate. The dislocation density was extremely low following the high-temperature solution treatment. The effect of the dislocation on the yield strength was insignificant. The results indicate that the increased yield strength of the N-alloying high-Mn austenitic steel benefited from the solid solution, the grain boundary, and the precipitation strengthening. 

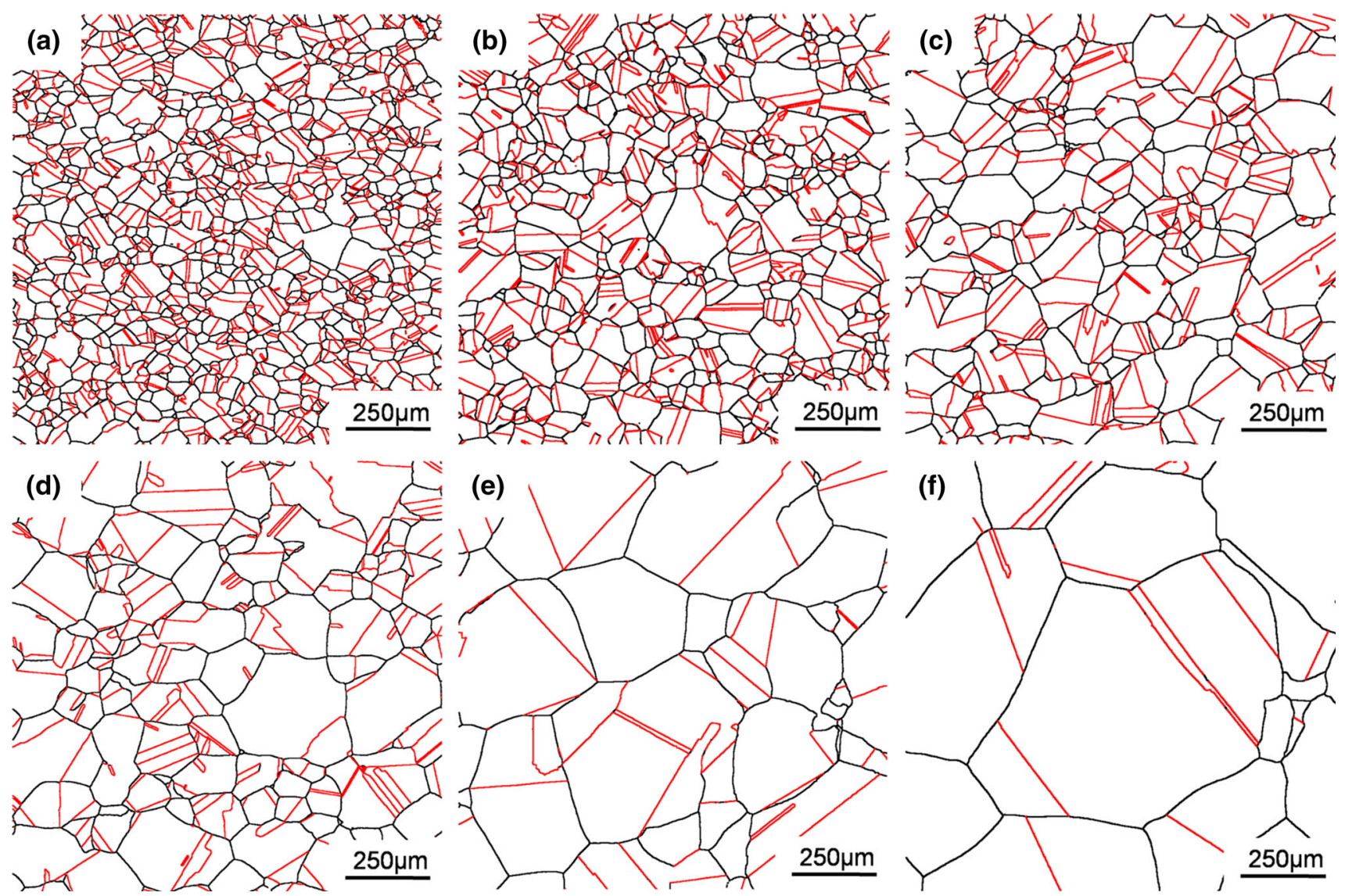

Fig. 11 EBSD images of the austenite grains with various ST. a $1323 \mathrm{~K}$, b $1373 \mathrm{~K}$, c $1423 \mathrm{~K}$, d $1473 \mathrm{~K}$, e $1523 \mathrm{~K}$, f $1573 \mathrm{~K}$. Black lines represent effective grains with a misorientation more than $15^{\circ}$, red lines represent annealing twins

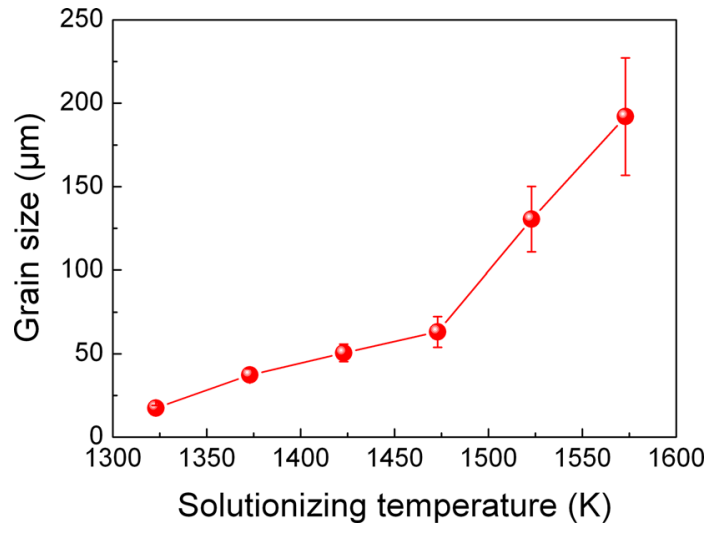

Fig. 12 Austenite grain size as a function of ST

The amount of the small-sized AlN precipitates was minor in the steels, so the effect of the AlN precipitate on the precipitation strengthening was weak. The yield strength was affected primarily by the grain size when the ST was increased. The grain size effect is determined by considering the Hall-Petch relationship:

$\sigma_{y}=\sigma_{0}+K_{\mathrm{HP}} d^{-0.5}$, where $\sigma_{\mathrm{y}}$ was the yield strength, $\sigma_{0}$ was the friction stress, $d$ was grain size in micrometers, and $K_{\mathrm{HP}}$ was the HallPetch coefficient. A smaller grain size had a more obvious effect on the grain-boundary strengthening. The effect that the grain refinement had on the grain-boundary strengthening in the ferritic steels was significant. But the effect of grain-boundary strengthening on the austenitic steels is not more significant than that on the ferritic steels [38]. The $K_{\mathrm{HP}}$ of the ferrite steels was approximately $550-780 \mathrm{MPa} \mu \mathrm{m}^{0.5}$ [32]. The $K_{\mathrm{HP}}$ of the austenitic steels was much smaller than the ferrite steels [39-43]. Kang et al. [44] reported that the $K_{\mathrm{HP}}$ of the $\mathrm{N}$-alloyed high-Mn steels without AlN precipitate is approximately 173-363 MPa $\mu \mathrm{m}^{0.5}$. Figure 13d shows the grain size dependence of the yield strengths of the experimental steels. The linear fitting yields a $K_{\mathrm{HP}}$ of the experimental steels which was $178 \mathrm{MPa} \mu \mathrm{m}^{0.5}$. This value was similar to that obtained by Kang et al. The results indicated that the refinement of the austenite grain size via the AlN precipitates resulted in a weak effect on the yield strength. 
Table 3 Tensile properties of the experimental steels with various ST

\begin{tabular}{lllll}
\hline Solutionizing temperature $(\mathrm{K})$ & Yield strength $(\mathrm{MPa})$ & Tensile strength $(\mathrm{MPa})$ & Elongation $(\%)$ & Strength-ductility balance $(\mathrm{GPa} \%)$ \\
\hline 1323 & 423 & 906 & 68 & 61.6 \\
1373 & 414 & 864 & 70 & 60.5 \\
1423 & 409 & 837 & 71 & 59.4 \\
1473 & 402 & 824 & 74 & 61.0 \\
1523 & 400 & 810 & 76 & 61.5 \\
1573 & 397 & 783 & 79 & 61.9 \\
\hline
\end{tabular}
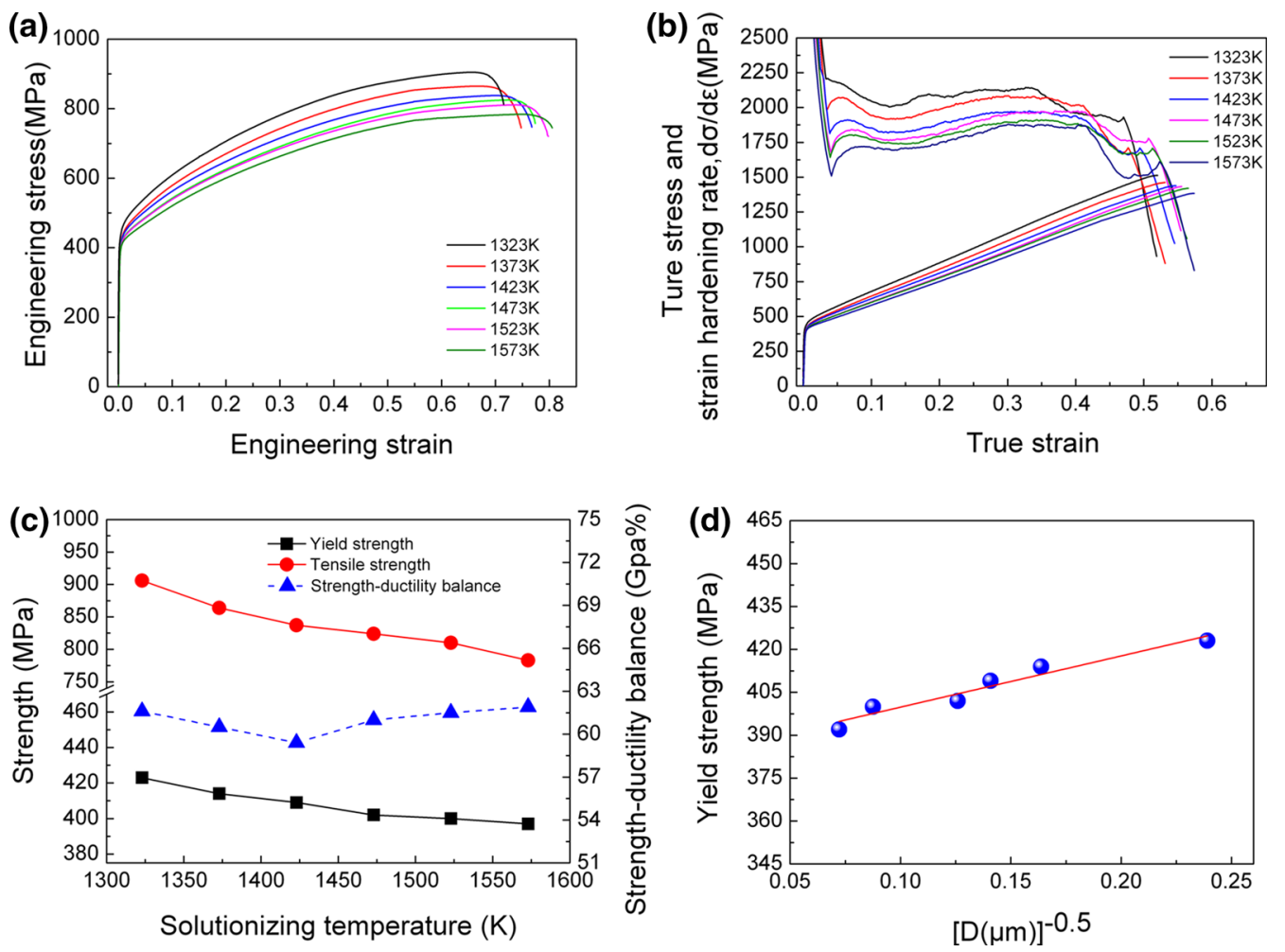

Fig. 13 Tensile properties of the experimental steels with various STs. a Engineering stress versus engineering strain curves, b true stress and strain hardening rate versus true strain curves, $\mathbf{c}$ tensile and yield strength as a function of ST, $\mathbf{d}$ grain size dependence of the yield strength of experimental steels

\section{Conclusion}

The control of $\mathrm{MnS}$ inclusions and AlN precipitates in a $\mathrm{N}$-alloyed high-Mn twin-induced plastic cryogenic steel by solution treatment was investigated. The solutionizing temperature (ST) increased from 1323 to $1573 \mathrm{~K}$, where the elongated MnS inclusion and large-sized AlN precipitate became spheroidized and dissolved. The aspect ratio of the MnS inclusions decreased as the ST increased and the number density increased. The impact toughness of the steels showed anisotropy and low impact energy values, due to the elongated MnS inclusions and large-sized AIN precipitates. The anisotropy was eliminated by the spheroidization of the $\mathrm{MnS}$ inclusions. The impact energy was improved by dissolving the large-sized AlN precipitate during the solution treatment. The austenite grain size increased when the dissolution of the AlN precipitate increased, but the effect of the grain size on the yield strength, toughness, and the strength-ductility balance was weak. In summary, the use of high-temperature solution treatment can eliminate the negative effect of the secondary phases.

Acknowledgements The authors gratefully acknowledge the financial support of the National Key Research and Development Program of China (Grant No. 2017YFB0305101). Thanks for Dr. E. X. Pu, Dr. Y. D. Gu, and Dr. S. T. Zhou for useful discussion. 


\section{References}

[1] S.S. Sohn, S. Hong, J. Lee, B.C. Suh, S.K. Kim, B.J. Lee, Acta Mater. 100, 39 (2015)

[2] L.Q. Chen, Y. Zhao, X.M. Qin, Acta Metall. Sin. (Engl. Lett.) 26, 1 (2013)

[3] W.W. Song, T. Ingendahl, W. Bleck, Acta Metall. Sin. (Engl. Lett.) 27, 546 (2014)

[4] J.S. Kim, J.B. Jeon, J.E. Jung, K.K. Um, Y.W. Chang, Met. Mater. Int. 20, 41 (2014)

[5] R. Fu, L. Qiu, T. Wang, C. Wang, Mater. Charact. 55, 355 (2005)

[6] E.D. Marquardt, J.P. Le, R. Radebaugh, Kluwer Cryocoolers. 11, 681 (2002)

[7] D. Jeong, S. Lee, I. Seo, J. Yoo, S. Kim, Met. Mater. Int. 21, 22 (2015)

[8] D. Jeong, S. Lee, I. Seo, J. Yoo, S. Kim, Met. Mater. Int. 21, 14 (2015)

[9] D.H. Jeong, S.G. Lee, W.K. Jang, J.K. Choi, Y.J. Kim, Metall. Mater. Trans. A 44, 4601 (2013)

[10] J. Frehser, C. Kubisch, Berg und Hüttenmännische Monatshefte. 108, 369 (1963)

[11] K.J. Irvine, T. Gladman, F.B. Pickering, J. Iron Steel Inst. 207, 1017 (1969)

[12] K. Frisk, Metall. Trans. A 21, 2477 (1990)

[13] N. Nakamura, S. Takaki, ISIJ Int. 36, 922 (1996)

[14] T. Tsuchiyama, S. Takaki, H. Ito, K. Kataoka, Metall. Mater. Trans. A 34, 2591 (2003)

[15] Q.L. Yong, Secondary Phases in Steels (Metallurgical Industry Press, Beijing, 2006), pp. 12-17

[16] T.J. Baker, J.A. Charles, J. Iron Steel Inst. 210, 680 (1972)

[17] W.M. Garrison, A.L. Wojcieszynski, Mater. Sci. Eng. A 464, 321 (2007)

[18] A. Ghosh, P. Modak, R. Dutta, D. Chakrabarti, Mater. Sci. Eng. A 654, 298 (2016)

[19] N. Cyril, A. Fatemi, B. Cryderman, SAE Int. J. Mater. Manuf. 1, 218 (2008)

[20] C. Temmel, N.G. Ingesten, B. Karlsson, Metall. Mater. Trans. A 37, 2995 (2006)

[21] F.G. Wilson, T. Gladman, Int. Mater. Rev. 33, 221 (1988)
[22] T.L. Anderson, Fracture Mechanics Fundamentals and Applications (CRC Press, Boca Raton, 2017), pp. 338-350

[23] N. Yuki, H. Shibata, T. Emi, ISIJ Int. 38, 317 (1998)

[24] K. Oikawa, H. Ohtani, K. Ishida, T. Nishizawa, ISIJ Int. 35, 402 (1995)

[25] X.J. Shao, X.H. Wang, C.X. Ji, H.B. Li, Y. Cui, G.S. Zhu, Int. J. Miner. Metall. Mater. 22, 483 (2015)

[26] N. Tsunekage, H. Tsubakino, Mater. Sci. Technol. 18, 964 (2002)

[27] Y.V. Murty, T.Z. Kattamis, R. Mehrabian, M.C. Flemings, Metall. Trans. A 8, 1275 (1977)

[28] D.R. Gaskell, D.E. Laughlin, Introduction to the Thermodynamics of Materials (CRC Press, Boca Raton, 2017), pp. 65-67

[29] X.J. Shao, X.H. Wang, M. Jiang, W.J. Wang, F.X. Huang, ISIJ Int. 51, 1995 (2011)

[30] D. Barbier, N. Gey, S. Allain, N. Bozzoloa, M. Humbert, Mater. Sci. Eng. A 500, 196 (2009)

[31] A.A. Benzerga, J. Besson, A. Pineau, Acta Mater. 52, 4623 (2004)

[32] X.J. Wang, X.J. Sun, C. Song, H. Chen, S. Tong, W. Han, P. Feng, Mater. Charact. 135, 287 (2018)

[33] X.J. Wang, X.J. Sun, C. Song, H. Chen, W. Han, P. Feng, Mater. Sci. Eng. A 698, 110 (2017)

[34] H. Gwon, J.K. Kim, S. Shin, L. Cho, B.C. De Cooman, Mater. Sci. Eng. A 696, 416 (2017)

[35] L. Mosecker, D.T. Pierce, A. Schwedt, Mater. Sci. Eng. A 642, 71 (2015)

[36] M. Ghasri-Khouzani, J.R. McDermid, Mater. Sci. Eng. A 621, 118 (2015)

[37] J.H. Kang, T. Ingendahl, J. von Appen, R. Dronskowski, W. Bleck, Mater. Sci. Eng. A 614, 122 (2014)

[38] O. Bouaziz, S. Allain, C. Scott, Scr. Mater. 58, 484 (2008)

[39] L.A. NorstrÖm, Met. Sci. 11, 208 (1977)

[40] R. Varin, K. Kurzydlowski, Mater. Sci. Eng. A 101, 221 (1988)

[41] E. Werner, Mater. Sci. Eng. A 101, 93 (1988)

[42] K. Kako, S. Takaki, K. Abiko, Mater. Trans. 43, 147 (2002)

[43] A. Di Schino, J. Kenny, Mater. Lett. 57, 1830 (2003)

[44] J.H. Kang, S. Duan, S.J. Kim, W. Bleck, Metall. Mater. Trans. A 47, 1918 (2016) 